\title{
Corticosterone Methyl Oxidase Deficiency Type 1 with Normokalemia in an Infant
}

\author{
Ala Üstyol1, Mehmet Emre Atabek1, Norman Taylor2, Matthew Chun-wing Yeung3, Angel O. K. Chan3 \\ ${ }^{1}$ Necmettin Erbakan University Faculty of Medicine, Department of Pediatric Endocrinology and Diabetes, Konya, Turkey \\ 2King's College Hospital, Clinic of Clinical Biochemistry, London, United Kingdom \\ 3The University of Hong Kong, Queen Mary Hospital, Clinic of Pathology, Pokfulam, Hong Kong
}

\section{WHAT IS ALREADY KNOWN ON THIS TOPIC?}

Isolated aldosterone synthase deficiency may result in lifethreatening salt-wasting and failure to thrive. To the best of our knowledge, the literature contains only one case of a Turkish patient with aldosterone synthase deficiency with confirmed mutation in the CYP I IB2 gene.

\section{WHAT THIS STUDY ADDS?}

We described a Turkish patient with aldosterone synthase deficiency presenting with failure to thrive and salt-wasting but with normal potassium levels in infancy. Diagnosis of aldosterone synthase deficiency was confirmed by mutational analysis of the CYPI IB2 gene.

\section{ABSTRACT}

Isolated aldosterone synthase deficiency may result in life-threatening saltwasting and failure to thrive. The condition involves hyperkalemia accompanying hyponatremia. Two types of aldosterone synthase deficiency may be observed depending on hormone levels: corticosterone methyl oxidase type 1 (CMO 1) and CMO 2. Herein, we describe a Turkish infant patient with aldosterone synthase deficiency who presented with failure to thrive and salt wasting but with normal potassium levels. Urinary steroid characteristics were compatible with CMO I deficiency. Diagnosis of aldosterone synthase deficiency was confirmed by mutational analysis of the CYP11B2 gene which identified the patient as homozygous for two mutations: c.788T>A (p.lle263Asn) and c.1157T>C (p.Val386Ala). Family genetic study revealed that the mother was heterozygous for $c .788 \mathrm{~T}>\mathrm{A}$ and homozygous for $\mathrm{c} .1157 \mathrm{~T}>\mathrm{C}$ and the father was heterozygous for both c.788T>A and c.1157T>C. To the best of our knowledge, this is only the second Turkish case with a confirmed molecular basis of type 1 aldosterone synthase deficiency. This case is also significant in showing that spot urinary steroid analysis can assist with the diagnosis and that hyperkalemia is not necessarily part of the disease.

Keywords: Corticosterone methyl oxidase, salt wasting, CYP11B2 gene, failure to thrive

Conflict of interest: None declared

Received: 07.01.2016

Accepted: 27.04 .2016

\section{Introduction}

Aldosterone is essential to life due to two important functions - sodium excretion and intravascular volume regulation. It is synthesized by aldosterone synthase and encoded by CYP11B2 gene on the long arm of chromosome 8. Beginning from 11-deoxycorticosterone in the zona glomerulosa of the adrenal cortex, aldosterone synthase catalyzes the sequential activities of

\section{Address for Correspondence}

Ala Üstyol MD, Necmettin Erbakan University Faculty of Medicine, Department of Pediatric Endocrinology and Diabetes, Konya, Turkey Phone: +90332 2236350 E-mail: alaustyol@gmail.com 
11ß-hydroxylase, 18-hydroxylase, and, finally, 18-methyl oxidase, the final three steps in aldosterone synthesis $(1,2)$. Classically, CYP11B2 was considered to utilize corticosterone generated from 11-deoxycorticosterone by action of 11ß-hydroxylase (CYP11B1), but 11-deoxycorticosterone proved to be the better substrate for CYP11B2 (2).

In infancy, aldosterone synthase deficiency generally takes the form of a life-threatening electrolyte imbalance. Failure to thrive, vomiting, and severe dehydration are commonly observed in children with the condition. Two types of aldosterone synthase deficiency have been described: corticosterone methyl oxidase type 1 (CMO 1) and CMO 2. These conditions can be differentiated by the presence of insufficient or excessive $18-\mathrm{OH}$-corticosterone, respectively. $\mathrm{CMO} 1$ is typically characterized by total suppression of aldosterone synthase with no detectable levels of aldosterone release. In contrast, some degree of aldosterone synthase activity persists in CMO 2 deficiency, and low to normal levels of aldosterone may be observed (3). This also explains why type 1 has a more severe course.

To the best of our knowledge, the literature contains only one case of a Turkish patient with aldosterone synthase deficiency with confirmed mutation in the CYP11B2 gene (4). In this report, we describe the second Turkish patient with aldosterone synthase deficiency who presented in infancy with failure to thrive and salt wasting. Urinary steroid characteristics were compatible with $\mathrm{CMO}$ I deficiency. Subsequent molecular genetic analysis on the CYP11B2 gene confirmed the diagnosis.

\section{Case Report}

Our patient was delivered normally at 38 weeks gestation with a birth weight of $3200 \mathrm{~g}$ and length of $50 \mathrm{~cm}$. The parents are Turkish and non-consanguineous. The patient presented at the age of 2 months with vomiting and failure to thrive. On examination, his body weight was $3.800 \mathrm{~g}$ (3rd percentile) and length was $53 \mathrm{~cm}$ (3rd to $10^{\text {th }}$ percentile). She had a normal female phenotype and no hyperpigmentation was noted. Blood pressure was $80 / 50 \mathrm{mmHg}$.

Laboratory examination revealed a plasma sodium level of $127 \mathrm{mmoh}$ (136-145), plasma potassium of $5.1 \mathrm{mmoh}$ (3.55.5), and normal blood urea nitrogen and plasma creatinine. Urinary sodium levels were elevated $(80 \mathrm{mmol} / \mathrm{L})$ despite hyponatremia. Hormonal evaluation revealed cortisol of $8 \mu \mathrm{g} /$ $\mathrm{dL}$ (5-25) and adrenocorticotropic hormone (ACTH) of $9.6 \mathrm{pg} /$ $\mathrm{mL}$ (10-55). Plasma renin activity was $128 \mathrm{ng} / \mathrm{mL} / \mathrm{h}$ (2.4-37) and plasma aldosterone $28 \mathrm{pg} / \mathrm{mL}$ (50-900). Aldosterone synthase deficiency was suspected. The patient was started on fludrocortisone $(0.05 \mathrm{mg} / \mathrm{day})$ and intravenous normal saline and responded well to treatment.

A spot urine sample was obtained before treatment, the steroid profile of which was analyzed using gas chromatography- mass spectrometry (GC-MS). This was carried out according to our previously published method (5). In brief, steroids were extracted, and conjugates were hydrolysed enzymatically using Helix pomatia digestive juice. The free steroid products were then re-extracted, and methyloxime-trimethylsilyl ether (MO-TMS) derivatives were prepared before analysis by GC-MS using a Perkin Elmer Clarus 500 system with an OV-1 column (Perkin Elmer, Beaconsfield, Buckinghamshire, UK). The steroid metabolites present in greatest quantities are quantified based on data obtained in cyclic scan mode. These comprise metabolites of androstenedione, dehydroepiandrosterone, progesterone, 17-hydroxyprogesterone, corticosterone, and cortisol.

Our patient's urine steroid profile was typical of aldosterone synthase deficiency type 1 in that tetrahydroaldosterone, the major metabolite of aldosterone, was undetectable and corticosterone metabolites were elevated relative to cortisol metabolites, but there were no increases of 18-hydroxylated corticosterone metabolites (Table 1).

\section{Genetic Study}

Written informed consent was obtained from the patient's parents to participate in the study.

\section{Polymerase Chain Reaction and DNA Sequencing}

Genomic DNA was extracted from peripheral leukocytes. All coding regions of CYP11B2 and the exon-intron splicing junction boundaries were amplified using the polymerase chain reaction method, followed by sequencing.

Sequence analysis of CYP11B2 showed that the patient was a homozygous for c.788T>A (p.lle263Asn) and c.1157T>C (p.Val386Ala) (Figure 1A, 1B). Family genetic study showed that the mother was heterozygous for $\mathrm{C} .788 \mathrm{~T}>\mathrm{A}$ and homozygous for c. $1157 \mathrm{~T}>\mathrm{C}$, while the father was heterozygous for both c.788T $>$ A and c. $1157 \mathrm{~T}>\mathrm{C}$.

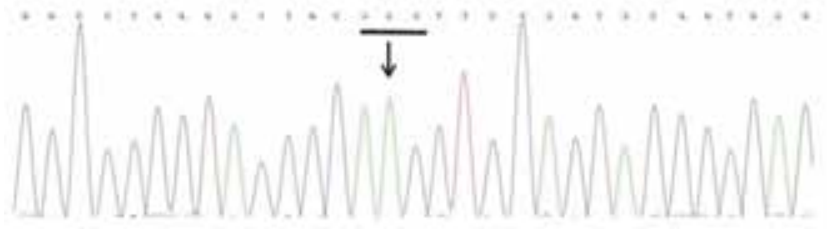

Figure 1A. Electropherogram of segment of the CYP11B2 gene showing the mutation c.788T>A (p.lle263Asn) in homozygous state in the patient. The affected codon is underlined

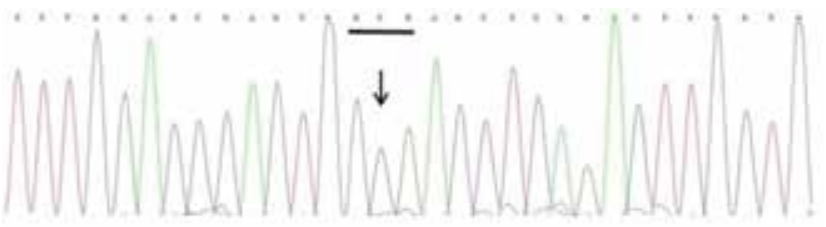

Figure 1B. Electropherogram of segment of the CYP11B2 gene showing the mutation c.1157T>C (p.Val386Ala) in homozygous state in the patient. The affected codon is underlined 


\begin{tabular}{|l|l|l|}
\hline \multicolumn{3}{|l|}{ Table 1. Urinary steroid profiles } \\
\hline Urine steroid profiles & Patient $\mu \mathbf{g} / \mathbf{L}$ & $\begin{array}{l}\text { Reference values } \\
\text { (mean } \pm \text { SD) }\end{array}$ \\
\hline THB & 268 & $53 \pm 24$ \\
\hline THA & 84 & $118 \pm 39$ \\
\hline allo-THB & 287 & $184 \pm 54$ \\
\hline THAld & Undetectable & \\
\hline THE & 305 & $702 \pm 256$ \\
\hline THF & 33 & $266 \pm 89$ \\
\hline $5 \alpha$ THF & 57 & $337 \pm 125$ \\
\hline$\alpha$-cortolone & 16 & $193 \pm 85$ \\
\hline$\beta$-cortolone+ $\beta$-cortol & 36 & $240 \pm 93$ \\
\hline$\alpha$-cortol & 5 & $94 \pm 43$ \\
\hline $\begin{array}{l}\text { Ratio corticosterone } \\
\text { metabolites/cortisol metabolites }\end{array}$ & 1.41 & $0.20 \pm 0.1$ \\
\hline $\begin{array}{l}\text { THB: tetrahydrocorticosterone, THA: tetrahydro-11-dehydrocorticosterone, THAld: } \\
\text { tetrahydroaldosterone, THE: tetrahydrocortisone, THF: tetrahydrocortisol, } \\
\text { SD: standard deviation }\end{array}$ & \multicolumn{2}{|l}{} \\
\hline
\end{tabular}

\section{Discussion}

Aldosterone synthase deficiency may rarely be encountered as a cause of hyponatremia and failure to thrive in infants. When the disease is suspected, it is of vital importance that fludrocortisone therapy be initiated in addition to appropriate fluid replacement. The presence of hyperkalemia is not essential in order to establish the diagnosis. Normal potassium levels despite hyponatremia have been reported in some patients with aldosterone synthase deficiency, similar to our case (6). One recent experimental study investigated the mechanisms involved in renal control of potassium homeostasis in complete aldosterone deficiency. The results showed that renal adaptation to a physiological $\mathrm{K}(+)$ load in aldosterone deficiency is possible by means of aldosterone-independent activation of the renal outer medullary $\mathrm{K}(+)$ channel and epithelial sodium channel. Angiotensin II may also contribute to this (7).

It is difficult in infants to collect urine samples over a 24-hour period. Spot urinary steroid profiling is also useful tool to diagnose aldosterone synthase deficiency and other congenital adrenal diseases (8). Our patient's urinary steroid profile was analyzed with a spot urinary sample, with findings consistent with $\mathrm{CMO} 1$ deficiency.

Cases of aldosterone synthase deficiency have been reported in various ethnic groups, including Europeans, North Americans, and Asians $(9,10,11,12)$. One previous case of aldosterone synthase deficiency in a patient of Turkish origin was reported from Japan (4). Ours is the first Turkish patient to be genetically confirmed and reported from Turkey. Type $1 \mathrm{CMO}$ was similarly present in the other Turkish patient. We were unable to obtain detailed clinical and laboratory information from the other Turkish patient for comparison with our own case, but the mutation in the other patient was different. We identified two homozygous mutations in CYP11B2, i.e. c.1157T>C and c.788T $>$ A. Family genetic study showed that while the father was heterozygous for these two mutations, the mother was heterozygous for c.788T>A and homozygous for c. 1157T >C.

In terms of the literature concerning the homozygous mutation, p.Val386Ala (c.1157T >C), the study of Pascoe et al (13) described the variant p.Val386Ala in Iranian-Jewish kindred previously, causing a small but reproducible reduction in the production of 18-hydroxycorticosterone in vitro. They hypothesized that the presence of another mutation is required if the gene is to become defective. Therefore, despite the mother is homozygous for p.Val386Ala, the overall genetic findings in her are still consistent with her being a carrier of aldosterone synthase deficiency. Since we were unable to study our patient's mother's urine steroid profile, we do not know whether subtle mineralocorticoid abnormalities were present. When we inquired into her medical history, including childhood, we learned that she had no marked adrenal insufficiency, had never undergone hyponatremia attack, and had not been hospitalized. However, there is a probability of mild mineralocorticoid deficiency in the mother's history. Another reason why the mother is today completely healthy may be that the condition gradually improves with declining renal tubular resistance to mineralocorticoids (3). Second homozygous non-synonymous variant in the patient is a novel c.788T $>A$ (p.1263N) change which is also predicted to be diseasecausing with a PolyPhen-2 score of 0.999 (http://genetics. bwh.harvard.edu/cgi-bin/pph2). This variant was neither found in ExAC nor in $1000 \mathrm{G}$.

In conclusion, this is the first report from Turkey of a Turkish patient with type 1 aldosterone synthase deficiency with a confirmed molecular basis and in which a spot urine steroid profile was used for making the diagnosis. Although aldosterone synthase deficiency is very rare, it is one of the diseases associated with hyponatremia and failure to thrive in infancy.

\section{Ethics}

Informed Consent: Written informed consent was obtained from the patient's parents to participate in the study.

Peer-review: Externally peer-reviewed.

\section{Authorship Contributions}

Concept: Ala Üstyol, Mehmet Emre Atabek, Design: Ala Üstyol, Mehmet Emre Atabek, Data Collection or Processing: Ala Üstyol, Analysis or Interpretation: Norman Taylor, Matthew Chun-wing Yeung, Angel O. K. Chan, Literature Search: Ala Üstyol, Writing: Ala Üstyol.

Financial Disclosure: The authors declared that this study received no financial support. 
Üstyol A et al.

Methyl Oxidase Deficiency Type 1

\section{References}

1. Curnow KM, Tusie-Luna MT, Pascoe L, Natarajan R, Gu JL, Nadler JL, White PC. The product of the CYP11B2 gene is required for aldosterone biosynthesis in the human adrenal cortex. Mol Endocrinol 1991;5:1513-522.

2. White PC, Curnow KM, Pascoe L. Disorders of steroid 11 $\beta$-hydroxylase isozymes. Endocr Rev 1994;15:421-438.

3. Miller WL, Auchus RJ. The molecular biology, biochemistry, and physiology of human steroidogenesis and its disorders. Endocr Rev 2011;32:81-151. Epub 2010 Nov 4

4. Nomoto S, Massa G, Mitani F, Ishimura Y, Miyahara K, Toda K, Nagano I, Yamashiro T, Ogoshi S, Fukata J, Onishi S, Hashimoto K, Doi Y, Imura H, Shizuta Y. CMO I deficiency caused by a point mutation in exon 8 of the human CYP11B2 gene encoding steroid 18-hydroxylase (P450C18). Biochem Biophys Res Commun 1997;234:382-385.

5. Taylor NF. Urinary steroid profiling. Methods Mol Biol 2006;324:159-175.

6. Jessen $\mathrm{CL}$, Christensen $\mathrm{JH}$, Birkebaek NH, Rittig $\mathrm{S}$. Homozygosity for a mutation in the CYP11B2 gene in an infant with congenital corticosterone methyl oxidase deficiency type II. Acta Paediatr 2012;101:519-525.

7. Todkar A, Picard N, Loffing-Cueni D, Sorensen MV, Mihailova M, Nesterov V, Makhanova N, Korbmacher C, Wagner $\mathrm{CA}$, Loffing J. Mechanisms of renal control of potassium homeostasis in complete aldosterone deficiency. J Am Soc Nephrol 2015;26:425-438. Epub 2014 Jul 28
8. Koyama Y, Homma K, Fukami M, Miwa M, Ikeda K, Ogata T, Hasegawa T, Murata M. Two-step biochemical differential diagnosis of classic 21-hydroxylase deficiency and cytochrome P450 oxidoreductase deficiency in Japanese infants by GC-MS measurement of urinary pregnanetriolone/ tetrahydroxycortisone ratio and $11 \beta$-hydroxyandrosterone. Clin Chem 2012;58:741-747. Epub 2012 Jan 24

9. White PC. Aldosterone synthase deficiency and related disorders. Mol Cell Endocrinol 2004;217:81-87.

10. Klomchan T, Supornsilchai $V$, Wacharasindhu S, Shotelersuk $V$, Sahakitrungruang T. Novel CYP11B2 mutation causing aldosterone synthase (P450c11AS) deficiency. Eur J Pediatr 2012;171:1559-1562. Epub 2012 Jul 17

11. Kondo E, Nakamura A, Homma K, Hasegawa T, Yamaguchi T, Narugami M, Hattori T, Aoyagi H, Ishizu K, Tajima T. Two novel mutations of the CYP11B2 gene in a Japanese patient with aldosterone deficiency type 1. Endocr J 2013;60:51-55. Epub 2012 Oct 28

12. Hui E, Yeung MC, Cheung PT, Kwan E, Low L, Tan KC, Lam KS, Chan AO. The clinical significance of aldosterone synthase deficiency: report of a novel mutation in the CYP11B2 gene. BMC Endocr Disord 2014;14:29.

13. Pascoe L, Curnow KM, Slutsker L, Rösler A, White PC. Mutations in the human CYP11B2 (aldosterone synthase) gene causing corticosterone methyloxidase II deficiency. Proc Natl Acad Sci U.S.A 1992;89: 4996-5000. 